\title{
Microwave radiation, seed germination and seedling growth responses in pepper (Capsicum annuum L.)
}

\begin{abstract}
The propagation of pepper (Capsicum аппиит L.) generally occurs through seed. Seed germination is a critical stage in the life-cycle of the plant, and often controls plant population dynamics. Here, we report an effective duration of exposure to microwave radiation to improve seed germination and growth indices of $C$. annuит. Two experiments were carried out at the seed germination and seedling growth stages. The results revealed that exposing the seed to $2,450 \mathrm{MHz}$ microwave frequency radiation for ten hours resulted in the highest seed germination percentages (SGP). This treatment led to a SGP of $64.7 \%$ after 14 day $\left(\mathrm{SGP}_{14}\right)$, with a mean germination time $\left(\mathrm{MGT}_{14}\right)$ of $9.5 \mathrm{~d}$. Although, other duration of exposure to microwave radiation had moderate effects on $\mathrm{SGP}_{14}$ from 42 to $64 \%$, they failed to reduce $\mathrm{MGT}_{14}$ values. Treating pepper seedlings with microwave frequency radiation revealed that $1 \mathrm{~h}$ of exposure increased plant growth indices (such as plant height and numbers of leaves), while longer exposure times ( $3 \mathrm{~h}$ or $4 \mathrm{~h}$ ), limited growth. Interestingly, longer durations of exposure to microwave frequency radiation changed the behaviour leaves. This technique may be therefore used to enhance seed germination percentages and seedling growth in pepper.
\end{abstract}

Keywords: Capsicum annuиm, chlorophyll content, germination rate, microwave frequency, microwave radiation
Volume 2 Issue 6 - 2018

\author{
Mohammad Mohsenkhah,' Masoud \\ Mahzoon,' Daryush Talei \\ 'Department of Electronic Engineering, Shiraz Pasargad Higher \\ Education Institute, Iran \\ 2Medicinal Plants Research Center, Shahed University, Iran \\ Correspondence: Daryush Talei, Medicinal Plants Research \\ Center, Shahed University, Tehran 331911865।, Iran, Tel \\ +982151214093, Fax +982151214091, \\ Email d.talail348@gmail.com
}

Received: October 04, 2018 | Published: November 22, 2018

\section{Introduction}

Applications of microwave energy in agriculture have increased over the past 50 years. ${ }^{1}$ The range of microwave frequency is between $300 \mathrm{MHz}-300 \mathrm{GHz}^{2,3}$ Due to their high frequency and short wavelength, microwaves are desirable for communication and radar applications. Microwaves are an interesting research subject, even in the $21^{\text {st }}$ century. Some research has been done on the effects of microwave on seed germination in species such as wheat (Triticum aestivum), Bengal gram (Cicer arietinum), green gram (Vigna radiate), and moth bean (Vigna aconitefolia), under microwave conditions. It has been reported that a threshold level of microwave energy and exposure time can improve seed germination and seedling vigour in plant species, ${ }^{4}$ while further increases in microwave frequency, energy or density caused a reduction in SGP and seedling vigour. ${ }^{4}$ Pepper (Capsicum annuum L.) is one of the most popular vegetables grown throughout the World, especially in South-East Asian countries such as Bangladesh, India, Pakistan, and Sri Lanka. Peppers are rich in vitamin $\mathrm{C}$, vitamin $\mathrm{A}$, and calcium compounds with anti-oxidant and anti-carcinogenic activities. ${ }^{5}$ Mature fruit also contain high concentrations of anti-oxidant phenolic compounds.

Microwave energy has been important for electrochemical-based investigations on biological behavior of seed germination ${ }^{6}$ and enzyme activities $^{7}$ in different plant species. The objective of the present study was to investigate the effects of microwave frequency radiation on seed in $C$. annuum seed by measuring SGP values and GR, as well as measuring various morphological and physiological traits.

\section{Materials and methods}

Seeds of Capsicum annuum L. were provided L. by the Agro Gene Bank of the University Putra Malaysia, Serdang, Malaysia.

\section{Microwave equipment}

The microwave antenna used was a $2.4 \mathrm{GHz}$ dipole antenna, 108.5 $\mathrm{mm}$ in length (GW.15.2113 model; USA) with a frequency controlled oscillator (ZX95-2490 model; Mini-Circuits; USA) including linear tuning characteristics such as a frequency range from $2,280-2,490$ $\mathrm{MHz}$, low phase noise, and low pushing, low pulling. ${ }^{2}$ The amplifier used (Model ZX60-3011; Mini-Circuits; USA) was a 50 $\Omega, 400-3,000$ $\mathrm{MHz}$ low-noise model. The other features were a high dynamic range, a wide band-width, a low noise $(1.5 \mathrm{~dB})$ feature, $1 \mathrm{~dB}$ compression, and medium IP3 (www.minicircuits.com). The detectors used (Models ZX47-50 and ZX47-50LN; Mini-Circuits; USA) were $50 \Omega$, from -50 $\mathrm{dB} \mathrm{m}$ to $+15 \mathrm{~dB} \mathrm{~m}$, and $10-8,000 \mathrm{MHz}$ co-axial power detector's with a low-noise DC output, $20 \mathrm{mVp}$-p type at $10 \mathrm{MHz}$, a high dynamic range, and a high band-width.

\section{Experimental design}

Two experiments were carried out at the seed germination and seedling growth stages from July - September 2012. The first experiment was based on a randomised complete block design (RCBD) with five treatments (five different durations of exposure to microwave frequency radiation at $2,450 \mathrm{MHz}$ ), each with three replicates. The five treatments were C (control), T1 (1 h), T2 (4 h), T3 $(7 \mathrm{~h})$, and T4 $(10 \mathrm{~h})$. All seeds were surface sterilised in $10 \%(\mathrm{v} / \mathrm{v})$ sodium hypochlorite for $10 \mathrm{~min},{ }^{8}$ then rinsed thoroughly with distilled water. Fifty seed were then soaked in each of 15 Petri dishes (five treatments $\times$ three replicates) containing filter paper moistened with sterile water. The Petri dishes were incubated in a controlled growth chamber (6MP6010; Adaptis, Conviron) at $28-30^{\circ} \mathrm{C}$ and a relative humidity of $70-85 \%$. The Petri dishes were then given five different durations of exposures to microwave radiation in a $60 \mathrm{~cm} \times 60 \mathrm{~cm} \times 60$ $\mathrm{cm}$ dimensions box covered in aluminium foil. Seed germination was recorded every day 8 day after exposure. Seed germination after 8 day 
$\left(\mathrm{SGP}_{8}\right)$ and 14 day $\left(\mathrm{SGP}_{14}\right)$ were calculated. The germination rate on day-14 $\left(\mathrm{GR}_{14}\right)$ was calculated by dividing the SGP obtained from each count by the number of days. The mean germination time $\left(\mathrm{MGT}_{14}\right)$ was calculated using the formula of Ellis \& Roberts ${ }^{9}$

$$
M G T=\sum D_{n} / \sum n
$$

Where MGT was the mean germination time, $\mathrm{n}$ was the number of seeds which germinated on day $\mathrm{D}$, and $\mathrm{D}$ was the number of each day counted from the start of germination. The design of second the experiment was the same as the first experiment. Seedlings were grown in the mixture of top soil, peat moss and sand $(2: 1: 1 \mathrm{v} / \mathrm{v})$ in $15 \mathrm{~cm}$ diameter pots. All plants at 10-12 leaf stage were exposed to different durations of microwave frequency irradiation, with three replicates. During the irradiation process, plants were incubated in a growth chamber at $28-30^{\circ} \mathrm{C}$, at a relative humidity of $70-85 \%$, with a $12 \mathrm{~h}$ photoperiod. All experiments used $2,450 \mathrm{MHz}$ microwave radiation at $1.58 \mathrm{~mW}$. The plants were placed $15 \mathrm{~cm}$ from the antenna and the durations of exposure were 1, 2, 3 and $4 \mathrm{~h}$, repeated each day for 20 day. Space restrictions due to the dimensions of the box meant that only six pots (one seedling per pot) could be treated. The pots were located $15 \mathrm{~cm}$ from omni-directional microwave antenna used for irradiation. Due to the circular pattern of irradiation, the pots surrounded the antenna (Figure 1). Treatments T1 and T2 were first. After $1 \mathrm{~h}$, the T1 samples were removed and replaced with the T4 pots. After $4 \mathrm{~h}$ from the start, the T2 samples were removed and the T3 samples were placed in the box, and finally after $7 \mathrm{~h}$ and $10 \mathrm{~h}$ the T3 and $\mathrm{T} 4$ samples were removed, respectively. The numbers of leaves (NL), plant heights (PH), mean leaf lengths (MLL), mean leaf width (MLW) and chlorophyll content were measured 10 day and 20 day after the end of the irradiation treatments.
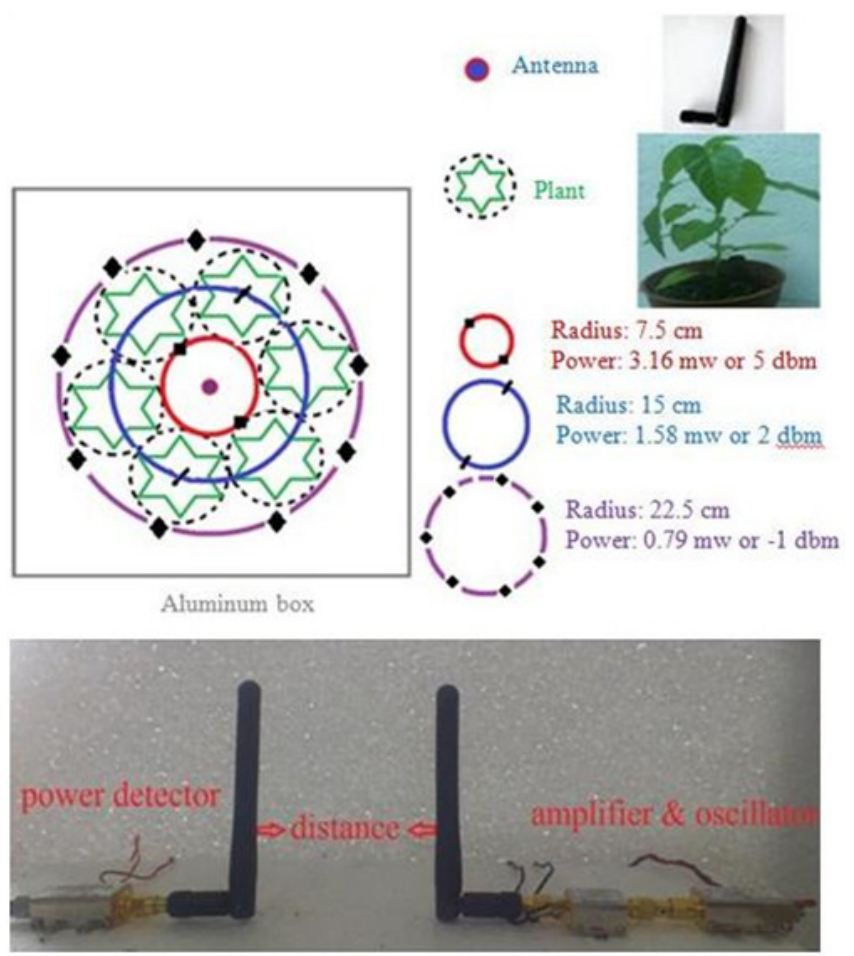

Figure I Location of pots and antenna inside the box.

\section{Determination of chlorophyll content}

Chlorophyll contents in leaves were measured using a chlorophyll-meter (XT-SPAD-502). The absorbance of chlorophyll was measured at $650 \mathrm{~nm}$ and non-specific absorbance was recorded at $940 \mathrm{~nm}$. Since the area measured by the SPAD-502 was only $6 \mathrm{~mm}^{2}$, a minimum of six reading were taken per leaf, then the average value was recorded.

\section{Statistical analysis}

Data were tested for normality using SAS Version $9 .{ }^{10}$ The data for the traits studied were analysed using analysis of variance and Duncan's multiple range test at significance level of $P \leq 0.01$.

\section{Results}

\section{Effect of different durations of exposure to microwave frequency radiation on seed germination in Capsicum annuum}

Different durations of exposure to microwave frequency radiation prior to seed germination significantly accelerated the rate of germination of $C$. annuum seed. Analysis of variance of the treatment effects on $\mathrm{SGP}_{8}, \mathrm{TSGP}_{14}, \mathrm{MGT}_{14}, \mathrm{GR}_{14}, \mathrm{RL}$, and SL showed that the treatments significantly affected the SGP of seed (Table 1). Seeds germinated successfully 8 day after $\mathrm{T} 1-\mathrm{T} 4$ with $\mathrm{SGP}_{8} 6-20 \%$. The $\mathrm{SGP}_{8}$ values showed that $10 \mathrm{~h}$ of microwave frequency radiation was the effective time to germinate the seed in which $20 \%$ of the seeds germinated after eight days (Figure 2a). This SGP value increased to $64.7 \%$ after 14 day (Figure $2 b$ ). Other durations of exposure to microwave frequency radiation showed varying effects as reflected by $\mathrm{SGP}_{8}$ values ranging from $6-14 \%$. Exposing the seeds for short times (4h) with microwave frequency improved the GR as shown by the $\mathrm{GR}_{\mathrm{a} 14}$ value (Figure 2c), but increasing the exposure time led to decrease in GR. The highest SL and RL were obtained at $4 \mathrm{~h}$ exposure to microwave frequency, while exposing the seeds for long time decreased the SL and RL (Figure 2d).

Table I Analysis of variance of the effect of different duration of exposure to microwave frequency radiation on germination traits in Capsicum annuum seed

\begin{tabular}{llllllll}
\hline \multirow{2}{*}{ S.O.V } & \multirow{2}{*}{ df } & \multicolumn{6}{l}{ Mean squares } \\
\cline { 3 - 8 } & & $\mathbf{S G P}_{\mathbf{8}}$ & $\mathbf{T S G P}_{14}$ & $\mathbf{M G T}_{14}$ & $\mathbf{G R}_{14}$ & $\mathbf{S L}_{14}$ & $\mathbf{R L}_{14}$ \\
\hline $\mathrm{R}$ & 2 & $12.8^{\text {ns }}$ & $17.87^{\text {ns }}$ & $0.07^{* *}$ & $0.13^{\text {ns }}$ & $0.42^{\mathrm{ns}}$ & $0.25^{\text {ns }}$ \\
$\mathrm{T}$ & 4 & $90.00^{* *}$ & $264.40^{* * *}$ & $0.45^{* *}$ & $1.83^{* *}$ & $2.5 \mathrm{I}^{\mathrm{ns}}$ & $7.40^{* *}$ \\
Error & 8 & 6.80 & 7.20 & 0.01 & 0.10 & 2.91 & 0.26 \\
\hline
\end{tabular}

** and ns, refer to $\mathrm{P} \leq 0.0 \mathrm{I}$ and non-significant, respectively. S.O.V: source of variance, df: degree of freedom, $\mathrm{R}$ : block, $\mathrm{T}$ : treatment, $\mathrm{SGP}_{\mathrm{s}}$ : seed germination percentage after 8 days, TSGP $_{14}$ : total seed germination percentage after 14 day, MGT $_{14}$ : mean germination time after 14 days, GR $_{14}$ : germination rate after 14 days, SL: shoot length, RL: root length.

\section{Effect of microwave frequency on the growth of Capsicum annuum}

Microwave frequency affected the plant height (PH) of $C$. annuum seedlings after $10 \mathrm{~d}$ exposure and $\mathrm{PH}$ and $\mathrm{NL}$ after $20 \mathrm{~d}$ exposure. Variation due to microwave frequency on $\mathrm{PH}$ and NL was highly significant $(P \leq 0.01)$, while there were no significant differences on 
other measured traits after 10 day and 20 day exposure (Table 2). All studied morphological traits increased under the effect of microwave frequency. Among the different durations of exposure to microwave frequency radiation, $1 \mathrm{~h}$ gave the highest PH, NL, MLL and MLW after 10 day and 20 day, followed by 4,3 and $2 \mathrm{~h}$ exposures. Increasing the exposure duration to microwave frequency radiation increased the values of studied morphological traits (Table 3). Mean of PH and NL after 20 day varied significantly between $21.33 \mathrm{~cm}$ (control) to 25.67 $\mathrm{cm}$ ( $1 \mathrm{~h}$ exposure) values and 14 (control) to 18.33 ( $1 \mathrm{~h}$ exposure), respectively (Table 3). Overall, $1 \mathrm{~h}$ exposure to microwave frequency radiation was best with respect to the morphological traits studied.
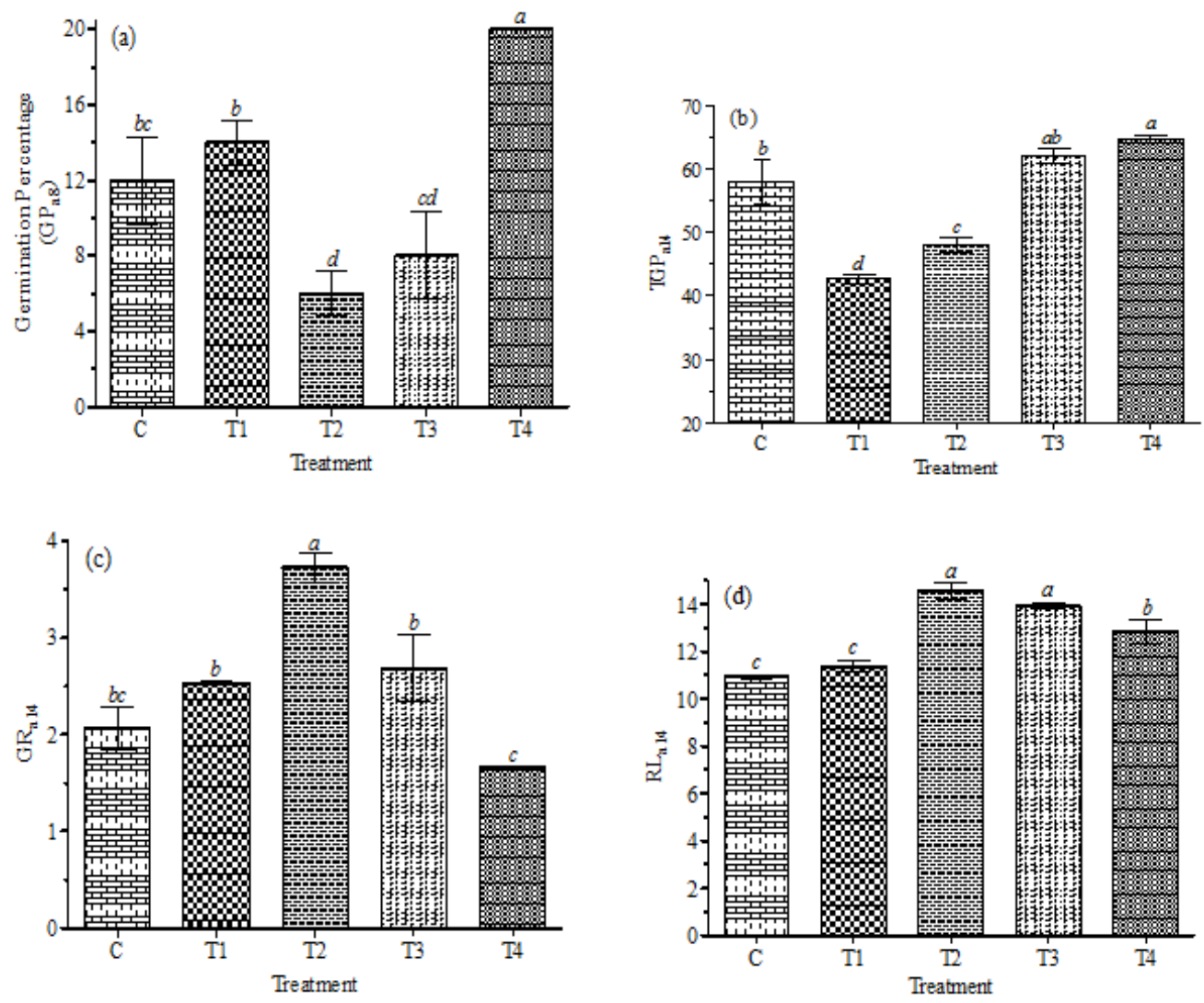

Figure 2 Seed germination in Capsicum annuum following different duration of exposure to microwave frequency. Germination percentage 8 day after treatment (a), Germination percentage 14 days after treatment (b), Germination rate 14 days after treatment (c), and Root length of germinated seeds (d). Mean values \pm S.E are from three independent replicates. Mean values in columns superscripted by different letters are significantly different by Duncan's multiple range test $(\mathrm{P} \leq 0.0 \mathrm{I})$. The treatments were: [C] Control, [TI] I h [T2] $4 \mathrm{~h},[\mathrm{~T} 3] 7 \mathrm{~h}$ and [T4] $10 \mathrm{~h}$ exposure to2450 $\mathrm{MHz}$ microwave frequency duration.

Table 2 Analysis of variance of the effects of the different duration of microwave on selected morphological traits in Capsicum annuum

\begin{tabular}{|c|c|c|c|c|c|c|c|c|c|c|c|}
\hline \multirow{2}{*}{ S.O.V } & \multirow{2}{*}{ df } & \multicolumn{5}{|c|}{ After 10 days } & \multicolumn{5}{|c|}{ After 20 days } \\
\hline & & NL & $\mathbf{P H}$ & MLL & MLW & CHLO & NL & PH & MLL & MLW & CHLO \\
\hline $\mathbf{R}$ & 2 & $2.40^{\mathrm{ns}}$ & $1.77^{\mathrm{ns}}$ & $1.24^{\mathrm{ns}}$ & $0.19^{\text {ns }}$ & $3.7 I^{\mathrm{ns}}$ & $3.27^{\mathrm{ns}}$ & $\left.1.9\right|^{\mathrm{ns}}$ & $4.40^{\text {ns }}$ & $0.65^{\mathrm{ns}}$ & $5.15^{\mathrm{ns}}$ \\
\hline $\mathbf{T}$ & 4 & $4.67^{\mathrm{ns}}$ & $8.95^{* k}$ & $3.54^{\mathrm{ns}}$ & $1.23^{\mathrm{ns}}$ & $8.0 \mathrm{I}^{\mathrm{ns}}$ & $11.17^{k k}$ & $7.38^{*}$ & $4.47^{\text {ns }}$ & $1.08^{\mathrm{ns}}$ & $6.73^{\mathrm{ns}}$ \\
\hline Error & 8 & 1.57 & 1.47 & 1.37 & 0.49 & 10.98 & 1.77 & 1.49 & 1.49 & 0.35 & 13.40 \\
\hline
\end{tabular}

**, * and ns, refer to P $\leq 0.01,0.05$ and non-significant, respectively. S.O.V: source of variance, df: degree of freedom, R: block, T: treatment, NL: number of leave, PH: plant height (cm), MLL: mean leaf length (cm), MLW: mean leaf width (cm), CHLO: chlorophyll ( $\left.\mu \mathrm{g} \cdot \mathrm{g}^{-1} \mathrm{FW}\right)$. 
Table 3 Comparison of different durations of exposure to microwave frequency radiation based on morphological traits in Capsicum annuum

\begin{tabular}{llllll}
\hline Treatment & $\mathrm{NL}_{20}$ & $\mathbf{P H}_{20}$ & $\mathbf{M L L}_{20}$ & $\mathbf{M L W}_{20}$ & $\mathbf{C H L O}_{20}$ \\
\hline Control & $14.0 \pm 0.0^{\mathrm{b}}$ & $21.3 \pm 0.3^{\mathrm{b}}$ & $9.0 \pm 0.2^{\mathrm{b}}$ & $4.6 \pm 0.2^{\mathrm{b}}$ & $35.8 \pm 0.0^{\mathrm{a}}$ \\
TI & $18.3 \pm 0.3^{\mathrm{a}}$ & $25.7 \pm 0.2^{\mathrm{a}}$ & $11.8 \pm 0.2^{\mathrm{a}}$ & $6.0 \pm 0.2^{\mathrm{a}}$ & $36.3 \pm 1.0^{\mathrm{a}}$ \\
T2 & $13.3 \pm 0.7^{\mathrm{b}}$ & $22.7 \pm 0.5^{\mathrm{b}}$ & $8.8 \pm 1.0^{\mathrm{b}}$ & $4.4 \pm 0.4^{\mathrm{b}}$ & $35.9 \pm 3.4^{\mathrm{a}}$ \\
T3 & $15.7 \pm 1.7^{\mathrm{b}}$ & $23.0 \pm 1.3^{\mathrm{b}}$ & $9.2 \pm 1.4^{\mathrm{b}}$ & $5.0 \pm 0.6^{\mathrm{b}}$ & $35.7 \pm 0.4^{\mathrm{a}}$ \\
T4 & $15.3 \pm 0.3^{\mathrm{b}}$ & $23.3 \pm 0.7^{\mathrm{b}}$ & $10.1 \pm 0.5^{\mathrm{b}}$ & $4.9 \pm 0.3^{\mathrm{ab}}$ & $39.2 \pm 2.7^{\mathrm{a}}$ \\
\hline
\end{tabular}

Data are mean values of three independent measurements \pm standard errors of mean. The different letters indicate significant differences based on Duncan's multiple comparison test at P $\leq 0.0$ I. NL: number of leaves, $\mathrm{PH}$ : plant height (cm), MLL: mean leaf length (cm), MLW: mean leaf width (cm) and CHLO: chlorophyll $\left(\mu \mathrm{g} \cdot \mathrm{g}^{-1} \mathrm{FW}\right)$.

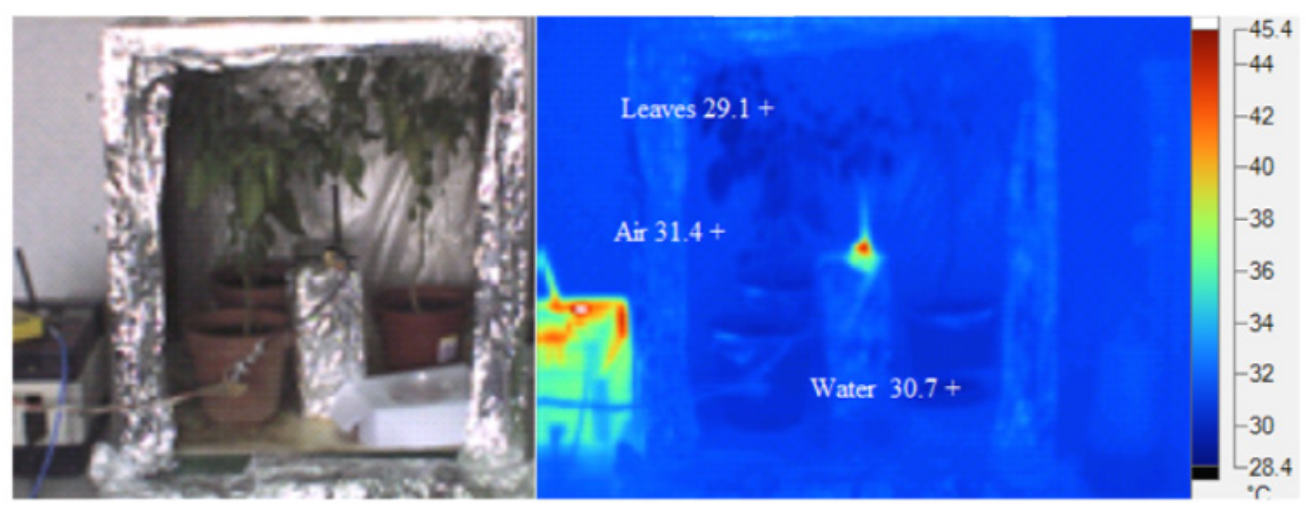

Figure 3 Thermograph examination after $4 \mathrm{~h}$ exposure to $2450 \mathrm{MHz}$ microwave frequency duration inside the box.

\section{Discussion}

Plants, especially vegetables, play an important role in our life and this issue has become urgent over the years. In this regard, germination is a critical stage in the life cycle of weeds, medicinal plants and crop plants, and often controls population dynamics, with major practical implications. ${ }^{10}$ The propagation of $C$. annuum L. generally occurs through seeds and germination of seeds depends on seed structures and the environmental factors such as temperature that affect the growth potential of the embryo. ${ }^{12}$ In order to determine the germination and growth index of Capsicum, germination and growth parameters like SGP, MGT, GR, PH, NL, MLL, MLW and chlorophyll content were evaluated under different durations of exposure to microwave frequency radiation. All the studied germination indices and growth parameters were affected by different durations of exposure to microwave frequency radiation. Thermograph examination revealed that increasing the exposure to microwave frequency led to increase in the temperature of the water inside the Petri dishes around the seeds. The temperature of the water inside the Petri dishes after $1 \mathrm{~h}$ and 10 $\mathrm{h}$ exposure to microwave frequency were 29 to $34.1^{\circ} \mathrm{C}$, respectively. Therefore it can enhance the movements of molecules and improve the growth potential of the embryo. Our results matched up well with the findings of Nelson, ${ }^{2} \operatorname{Tran}^{13}$ and Vadivambal, ${ }^{1}$ who showed that microwave frequency radiation, facilitated the GR and growth indices of $C$. annuиm. This may be due to the positive effects of microwave frequency on water absorption and other biochemical processes. ${ }^{2}$ The temperature of the environmental conditions inside the box after $1 \mathrm{~h}$ and
$4 \mathrm{~h}$ exposure to microwave frequency were $29-31.4{ }^{\circ} \mathrm{C}$, respectively, and the temperature of the plant (leaves) inside the box after one and four hours were $28.2-29.1{ }^{\circ} \mathrm{C}$ (Figure 3). Increasing durations of exposure to microwave frequency radiation led to linear increase in temperature of environment around the plant inside the box, while the temperature of plant leaves was non-linear. In the initial period (after 1 h), the plants were in the process of adapting to microwave frequency due to increase in temperature, but in the next periods, the plants were able to withstand the temperature due to the release energy, which may be led to limitation in plant growth. Under short exposure to microwave frequency $(1 \mathrm{~h})$, the energy facilitated the plant growth as indicated by the increase in certain measured morphological traits such as PH and NL in the plant similar to the results of Ferriss, ${ }^{14}$ while under long exposure time of microwave frequency $(3 \mathrm{~h}$ and 4 h) the growth was limited. Interestingly, long exposure to microwave frequency caused changes in performance of leave, which may lead to decline in photosynthesis capacity, respiration, and disturb metabolism of several cellular components such as protein synthesis. According to Basra, ${ }^{15}$ and Baskin \& Baskin ${ }^{16}$ reports, germination stage needs higher temperature than growth stage in the plants. Because of this long exposure duration led to increase in the SGP and GR, while short exposure led to improve on growth indices. Our results revealed the important role of microwave frequency in improving the seed SGP, GR and plant growth. The overall results suggested that $10 \mathrm{~h}$ and $1 \mathrm{~h}$ exposure to microwave frequency as the best exposure to microwave frequency for germination and growth of C. annuum, respectively. ${ }^{17}$ 


\section{Conclusion}

The most impact of microwave radiation on the seed germination had the greatest effectors after $10 \mathrm{~h}$ exposure and on seedlings growth after $1 \mathrm{~h}$ exposure. The mechanisms of microwave frequency on seed germination and seedling growth are unknown. But according to positive effects of the microwave frequency on SGP GR and plant growth it can be concluded that the microwave energy can increase the temperature surrounding the seeds and plants and facilitate the SGP, GR and plant growth. Interestingly, long exposure to microwave frequency caused changes in performance of leaves, which can be applied to produce mutant plants in plant breeding programme.

\section{Acknowledgments}

None.

\section{Conflicts of interest}

Author declares that there is no conflict of interest.

\section{References}

1. Vadivambal R, Jayas D, White N. Wheat disinfestation using microwave energy. Journal of Stored Products Research. 2007;43: 508-514.

2. Nelson S. Potential agricultural applications for RF and microwave energy. Transactions of the ASAE. 1987;30(3):818-822.

3. Wang S, Tang J. Radio frequency and microwave alternative treatments for insect control in nuts: a review. Agricultural Engineering Journal. 2001;10:105-120.

4. Talei D, Valdiani A, Maziah M Germination Response of MR 219 Rice variety to different exposure times and periods of $2450 \mathrm{mhz}$ microwave frequency. The Scientific World Journal. 2013;1-7.

5. Howard L, Talcott S, Brenes C, et al. Changes in phytochemical and antioxidant activity of selected pepper cultivars (Capsicum species) as influenced by maturity. Journal of Agricultural and Food Chemistry. 2000;48:1713-1720.
6. Zhao Y, Liu J, Qin H, et al. The effect of electrochemical processing on biological behavior of wheat seeds germination. International Journal of Electrochemical Science. 2012;7:11313-11322.

7. Benlloch TM, Igual M, Rodrigo D, et al. Comparison of microwaves and conventional thermal treatment on enzymes activity and antioxidant capacity of kiwifruit puree. Innovative Food Science and Emerging Technologies. 2013;19:166-172.

8. Talei D, Mihdzar AK, Khanif MY, et al. Effects of different surface sterilizers on seed germination and contamination of king of bitters (Andrographis paniculata Nees.). American-Eurasian journal of agricultural and environmental sciences. 2011;10:639-643.

9. Ellis RH, Roberts EH. The quantification of ageing and survival in orthodox seeds. Seed Science Technology. 1981;9:373-409.

10. SAS-Institute-Inc. SAS, User's Guide. Release 91. SAS Institute, Cary, NC, USA; 2009.

11. Keller M, Kollmann J. Effects of seed provenance on germination of herbs for agricultural compensation sites. Agriculture, Ecosystems and Environment. 1999;72:87-99.

12. Koornneef M, Bentsink L, Hilhorst H. Seed dormancy and germination. Current Opinion in Plant Biology. 2002;5:33-36.

13. Tran VN. Effects of microwave energy on the strophiole, seed coat and germination of Acacia seeds. Functional Plant Biology. 1979;6:277-287.

14. Ferriss R. Effects of microwave oven treatment on microorganisms in soil. Phytopathology. 1984;74:121-126.

15. Basra AS. Handbook of seed science and technology. Haworth Press, New York, USA. 2006;795.

16. Baskin CC, Baskin JM. Seeds: ecology, biogeography, and evolution of dormancy and germination. Academic Press. 1988:665.

17. Dielectric properties of agricultural products and some applications. Research in Agricultural Engineering. 2008;54:104-112. 